\title{
Racismo, cultura y prensa: el diario Crónica durante la Revolución Libertadora, Jujuy, Argentina
}

Racism, culture and the press: the Crónica newspaper during the Revolución Libertadora period (Liberating Revolution), Jujuy, Argentina

\section{Fernando Aníbal Castillo}

Universidad Nacional de Jujuy. Unidad de Investigación en Historia Regional. Consejo Nacional de Investigaciones científicas y técnicas (CONICET).

unihr@ishir-conicet.gov.ar

Resumen: El derrocamiento del peronismo y la posterior instauración del régimen designado "Revolución Libertadora" favorecieron la emergencia de un proceso de transformación de los discursos de carácter público, expresados fundamentalmente en la prensa. El proceso de desperonización supuso una serie de innovaciones en la esfera pública de manera tal que se sustituyó toda referencia al régimen destituido en beneficio de una trama discursiva de manifiesta naturaleza antiperonista.

En este marco se desarrolló un proceso de impugnación de los elementos vinculados al peronismo; la prensa operó como un actor enérgico que interpeló al Estado, demandándole la supresión de los vestigios del gobierno anterior, entre estos, los nombres de los lugares públicos.

La campaña desatada por los diarios de Jujuy comportó, en el caso específico de Crónica, la exigencia de redenominación y renormalización de espacios nominados mediante apelaciones de naturaleza indígena, como la plaza Túpac Amaru. Los fundamentos del medio gráfico se hallaban en la explícita condición de salvajismo que el mismo diario le asignaba al personaje mencionado.

Este tratamiento peyorativo tuvo antecedentes durante el gobierno peronista y formó parte de los principios constitutivos 
del antiperonismo. Esta práctica se expresó durante este período en la reedición de la histórica consigna "civilización y barbarie".

El presente trabajo se orienta a determinar las características de la dimensión racista del antiperonismo en función de la constitución de sus representaciones específicas en torno a particulares fenómenos históricos.

Palabras clave: Antiperonismo; Prensa; Racismo

\section{Abstract:}

The overthrow of Peronism and the subsequent establishment of the Revolución Libertadora regime (Liberating Revolution) favored the emergence of a process of transformation of public speech, mainly issued by the press. The deperonization process involved a series of innovations in the public sphere in a way that all references to the deposed regime were replaced to favor an openly antiperonist discourse.

In this framework, a process was started to impugn those elements linked to Peronism; the press took an active role questioning the State and demanding the suppression of any traces of the previous government, such as the names of public places. The campaign promoted by Jujuy newspapers, specifically the Crónica, demanded renaming and renormalizing spaces named after indigenous appeals, such as the Plaza Tupac Amaru. The newspaper founded this change on the explicit savagery condition assigned by the newspaper to the person referred to in the name of the place.

This pejorative treatment can be traced back during the Peronist government and became part of the constitutive principles of Antiperonism. This practice was expressed during this period by reissuing the historic slogan "civilization and barbarism" ("civilización y barbarie").

This paper is aimed at determining the characteristics of the racist dimension of Antiperonism depending on the constitution of its specific representations about particular historical events.

Keywords: Antiperonism; Press; Racism.

Fecha de recepción: 17-6-13 Fecha de reenvios 26-01-14, 25-02-14, 27-03-14, 31-03-14

Fecha de aceptado: 06-05-14 Fecha de publicación: 09-06-14

http://dx.doi.org/10.15359/abra.34-48.3 


\section{Presentación: problemática y planteo}

En septiembre de 1955 el gobierno peronista fue depuesto por un levantamiento militar. El derrocamiento del régimen denominado "justicialista" y la posterior instauración de una tutela gubernamental autodesignada "Revolución Libertadora" favorecieron -en un marco de múltiples mutaciones ejecutadas sobre el orden instituido por Perónla emergencia de un proceso de transformación y restructuración de los discursos, fundamentalmente en el ámbito de la prensa. La desperonización operada sobre la esfera pública supuso una serie de innovaciones de manera tal que se sustituyó toda referencia a la administración destituida en beneficio de una trama discursiva de manifiesta naturaleza antiperonista.

En este contexto de impugnación de los elementos vinculados al peronismo, la prensa operó como un actor enérgico que interpeló al Estado "revolucionario", demandándole la supresión de los vestigios del gobierno anterior, entre estos, los nombres de los lugares públicos. La campaña desatada por los diarios de la provincia de Jujuy comportó, en el caso específico de Crónica, la exigencia de redenominación y normalización de espacios nominados mediante apelaciones de raigambre indígena, como la plaza designada "Túpac Amaru". Los fundamentos del medio gráfico en cuestión abrevaban en la explícita condición de salvajismo que el mismo diario le asignaba al personaje mencionado.

Las preocupaciones por lo indígena no fueron propiedad exclusiva de los actores antiperonistas; antes bien, algunos agentes del peronismo también habían hecho ostensible una mirada despectiva de los originarios. No obstante, la mirada peyorativa que condenaba a estos actores a la "barbarie" supuso uno de los elementos constitutivos del antiperonismo, que se expresó durante los años peronistas a partir de la estructuración del espacio social y mediante el otorgamiento del carácter civilizado a los opositores de Perón.

La peculiaridad de Crónica radicaba en la desarticulación de los principios de junción entre la hispanidad y el catolicismo como fundamentos conjuntos de la civilización, promoviendo en paralelo el solapamiento de las consideraciones racistas originadas en una perspectiva hispanista con el antiperonismo. De esta forma, el diario mencionado reprodujo ciertos principios antiperonistas, asumiendo el rol de vocero de aquellos 
sectores que entendían el duelo con el peronismo desde una perspectiva tanto política como cultural y racial.

El presente trabajo se orienta a determinar las características de la dimensión racista del antiperonismo en función de la constitución y reproducción de sus representaciones específicas en torno a determinados fenómenos históricos a través del estudio de los discursos de la prensa en la provincia de Jujuy y del análisis particular de Crónica. Sugerimos conjeturalmente que la construcción de tales enunciados se fundó en la intercalación de los siguientes elementos: la prédica desperonizadora, una tradición racista y difamatoria de lo originario, y la omisión del catolicismo como principio integrador de la sociedad.

\section{Apuntes sobre la provincia de Jujuy, Argentina}

Localizada en el noroeste de Argentina, lindante con Bolivia y Chile, la provincia de Jujuy constituye una zona de frontera, rica en diversidad cultural y ecológica. Su territorio es atravesado por disímiles regiones (puna, quebrada, valles centrales y valles orientales), cada una con sus particularidades identitarias y sus entornos naturales. Estas áreas han dispuesto de condiciones específicas para distintas prácticas productivas, como la minería en la Puna y enclaves azucareros en los valles orientales.

Estas actividades se expresaban en múltiples escalas, que involucraban desde economías de subsistencia hasta explotaciones agroindustriales de envergadura. Desde fines del siglo XIX, este distrito asistió a un proceso de transformación de su estructura económica; a partir de la aplicación de recursos tecnológicos, se fomentó la industrialización de la producción de azúcar, estableciéndose así el predominio de esta última junto a los centros de producción minera (cuyos propietarios eran los mismos dueños de los ingenios) (Teruel, 2006).

En los ingenios azucareros la fuerza de trabajo se reclutaba en la Puna mediante conchabadores, cuyos mecanismos de movilización de obreros apelaba habitualmente a argucias como el endeudamiento forzado, el trabajo en las plantas azucareras como forma de pago de los arrendamientos de las tierras y la violencia física; de esta manera se compelía a los pobladores de la Puna a ocuparse en los ingenios, en particular en el desarrollo de las labores de zafreros, recolectando la 
caña de azúcar. En este marco, la explotación recayó en gran medida sobre indígenas, levados tanto de la región puneña como de los valles próximos a tales establecimientos.

Una de las características socio-políticas fundamentales de Jujuy estuvo dada en la considerable injerencia que las empresas azucareras imprimieron en su devenir (Kindgard, 2001). La intrusión aludida se manifestó en la impronta que -representados por los partidos conservadores- fomentaron en las políticas estatales. Tales condiciones cambiarían a partir de junio de 1943. Un alzamiento militar daría lugar a una nueva tutela; de carácter nacionalista, anticomunista y clerical, emergió con pretensiones de inyectar equilibrio en las relaciones entre capital y la fuerza laboral. Al procurar seguir tal trayectoria, el nuevo gobierno, bajo la influencia notoria de Perón, terminó generando numerosos beneficios para los trabajadores.

En este marco, aunque sin perder mayormente peso en la apropiación de la riqueza de la provincia, los sectores vinculados a la manufactura azucarera verían menoscabados sus intereses. La sanción del Estatuto del peón y la promulgación del aguinaldo (junto a la predisposición del gobierno a intervenir a favor de los trabajadores en los conflictos con la patronal) en un principio, y las subsiguientes expropiaciones de las que fueron objeto las tierras de los ingenios y el control ejercido sobre el proceso de conchabo dieron cuenta de la posición que había asumido el Estado.

La emergencia del peronismo en Jujuy se constituyó en función de la gravitación que ejercían tales sectores del capitalismo vernáculo: las fuerzas que se agruparon en torno al proyecto de Perón se constituyeron en función de la oposición manifiesta a la "oligarquía" (Kindgard, 2001). Detrás del líder de los descamisados se parapetaron el ala disidente del Partido Radical y el laborismo. A diferencia de lo acaecido en otras regiones, en Jujuy la coalición que apoyó a Perón no contó con la participación del conservadurismo. Desde sus albores y durante la siguiente década, el peronismo se impondría implacablemente en las contiendas electorales.

En esta provincia, también se asistió a un proceso de "peronización"; la constitución de un espacio exuberante en imágenes y consagraciones vinculadas al régimen y sus dirigentes fue plausible en función de la 
formación de condiciones específicas, que en definitiva favorecieron la emergencia de tales discursos. Asimismo, el espacio público fue objeto de numerosas mutaciones en lo que concierne a las nominaciones de los lugares públicos. Sus calles, avenidas, plazas, escuelas y otros espacios fueron nombrados siguiendo el principio de autoconsagración de los actores y obras ligadas al peronismo. La delimitación de la prensa como ámbito estrictamente reservado a la amplificación de los discursos de corte peronista contribuyó del mismo modo a la eliminación de los elementos antagonistas del espacio público.

En función de la gravitación que en el proyecto peronista adquirirían los asalariados, sus intereses fueron representados en la esfera pública. De tal manera que reforzaba el carácter herético del peronismo-cuya primera expresión disruptiva en términos de política y espacio se manifestó el 17 de octubre de $1945-1$ se constituyó la irrupción de trabajadores y mujeres en un espacio que había impuesto límites físicos y simbólicos a la participación de estos últimos actores. Al abrirse la participación a sectores antes postergados, el espacio público no solo adquirió nuevos matices, sino que en rigor se vio profundamente alterado. Los trabajadores y mujeres eran ahora actores cuyas intervenciones operaban en el plexo discursivo y demandaban, dada su radical importancia en los procesos de crecimiento de la nación, tácitamente la puesta en circulación de sus discursos. Los temas apremiantes para estos sujetos colectivos devinieron entonces como componentes inseparables de las agendas de la prensa; sus demandas e interpelaciones pasaron a engrosar las columnas de los medios gráficos.

La representación de actores antes postergados tuvo en el caso de los indígenas un carácter contradictorio. El radicalismo intransigente que nutrió al peronismo a mediados de los cuarenta se había caracterizado desde hacía décadas en esta provincia por su preocupación por los indígenas (Kindgard, 2004). Tal tradición se puso de manifiesto no bien consagrado el triunfo peronista, mediante la presentación de un proyecto para la entrega de tierras a los habitantes de la puna jujeña. Por otro lado, otros cuadros del peronismo no expresaron profuso entusiasmo por la preconización de los intereses de los originarios.

1 En la fecha mencionada, frente a la detención de Perón, se produjo una serie de movilizaciones masivas en las cuales sus simpatizantes pidieron su liberación. Los manifestantes coparon la Plaza de Mayo, de gran significación en Argentina, y ganaron las calles en diversas ciudades en un acto que se considera como la irrupción de los sectores populares en la esfera pública, y, asimismo, uno de los hechos fundacionales del peronismo. Dentro de la vasta producción bibliográfica al respecto, ver: Torre (1995). 


\section{Peronismo, antiperonismo y el dilema de la civilización y barbarie}

De acuerdo con Torre (2002), la emergencia del peronismo inauguró una novedosa instancia en lo que concierne a las luchas estructurantes en Argentina. Señala Torre que en la medida que el peronismo se constituyó como fuerza política, removió la tradicional relación de oposición entre el Partido Radical y los representantes del conservadurismo. De esta manera, se efectuó un pasaje hacia disputas "con contenidos de clase y tributaria de los conflictos que acompañaron la expansión de los derechos sociales y la integración política y social de vastos sectores del mundo del trabajo" (Torre, 2002, p. 13).

La conflagración mencionada tomó tonalidades específicas desde la perspectiva del antiperonismo. Dos formas de estructurar las acciones beligerantes entre unos y otros actores se pusieron de manifiesto; primero, en la reactualización en este país de la pugna entre el fascismo y las fuerzas aliadas; luego, en la relación entre civilización y barbarie (también resignificada a la luz del nuevo contexto nacional).

La relación entre peronistas y antiperonistas, desde los albores del gobierno castrense iniciado en junio de 1943, giró -de acuerdo con la mirada de los segundos- en función de las lealtades o confrontación a los principios de la libertad y la democracia. Dado el carácter autoritario del nuevo gobierno y la simpatía de algunos de sus dirigentes por las potencias del Eje, el bando aliadófilo -en el que se parapetaban organismos vinculados a la tradición liberal- no tardaron en motejarlo como nazi. En este sentido, el Partido Socialista fue uno de los organismos precursores que sentaría las bases para definir al peronismo taxativamente como un gobierno de corte fascista (García Sebastiani, 2005; Herrera, 2005).

Al respecto, Svampa (2010) señala que las disputas incorporaron otro principio de estructuración, en función de la emergencia de las masas peronistas en la escena política. Destaca la autora que los eventos de octubre de 1945 favorecieron la redefinición del conflicto. Tales acontecimientos inscribieron la emergencia de actores desprovistos antaño de apropiación de la palabra en el espacio público, de cuerpos ilegítimos en el reconocimiento forzado por su advenimiento. 
La plaza de mayo (...) se convierte en el centro simbólico del movimiento peronista abarcando una pluralidad de significados. Es la representación gráfica de la ciudad invadida por las multitudes adictas: migrantes internos, cabecitas, grasas, descamisados. Es la repetición de la revancha del Interior sobre la Capital. (...) Pero, para gran parte de las clases medias y altas urbanas, resulta la póstuma encarnación de la barbarie sarmientina lavándose "las patas en las fuentes. (Ciria, 1983, pp. 276277)

El 17 de octubre constituyó una ruptura en la relación entre ambos sujetos colectivos, en la medida que los actores que penetraron en la esfera pública fueron subsumidos por el antiperonismo bajo la condición de la no civilización.
El fantasma de la barbarie tomó cuerpo en las masas peronistas. Es el "aluvión zoológico", el "lumpenproletariado", "los cabecitas negras", los "descamisados". Es, al mismo tiempo, algo más que aquellas masas nazi-fascistas en comunicación directa con su líder desde alguna plaza histórica: evoca, ciertamente, la invasión de la Argentina mestiza a la clara y culta ciudad portuaria; es, en otros términos, la barbarie no extirpada. (Svampa, 2012, p. 320)

Svampa (2012) concluye que la lucha entre democracia y dictadura "fueron inscriptos en la tradición política argentina bajo el signo de la imagen sarmientina" de civilización y barbarie (p. 320). Las consideraciones de Sarmiento (escritor y político argentino de suma influencia de mediados del siglo XIX en adelante) sobre la barbarie son categóricas: un mal arraigado en las figuras de los indígenas y los gauchos. Por otro lado, la asociación que Sarmiento trazó entre hispanidad y barbarie -cabe acotar-no deja dudas: existía entre una y otra una relación de causalidad.

\section{Hispanidad, catolicismo y peronismo}

Lo hispánico fue defendido por cierto sector del peronismo; esgrimido con argumentos y finalidades diversas, se constituyó en fundamento de ciertos proyectos de actores que en los albores del régimen justicialista 
lo apoyaban. La salvaguardia de los valores españoles se inscribía fundamentalmente en la preconización de la educación de carácter religioso. Al respecto, Ciria (1983) sostiene que en el marco del debate por la ratificación de ley de educación religiosa -sancionada primeramente por el gobierno militar consagrado por las armas el 4 de junio de 1943-, sus adalides detractaban la ley 1420 , que regulaba la educación pública desde fines del siglo XIX. Considerada como exponente del laicismo y el liberalismo, tal normativa era acusada de contrariar los principios de la hispanidad y el catolicismo.

Promulgada en diciembre de 1943, la instrucción religiosa fue resguardada por el bloque oficialista en función de la connivencia entre el peronismo y la iglesia. Señala Bianchi (1992) que tales argumentos se cimentaban sobre los postulados del catolicismo integrista hispanófilo, que pretendía no ceder ante la secularización y advenir como principio estructurador de la sociedad. La tríada hispanidad, catolicismo y nacionalidad se oponía categóricamente a la orientación liberal, a la cual consideraba como uno de los fundamentos de la desintegración social; esto es, como un elemento plausible de romper con la unidad de la trilogía mencionada.

La preconización de la tradición hispánico-católica conllevó (además de la defenestración de la ley 1420, el enaltecimiento del orden social y la condena al comunismo) el retorno a un estado primigenio:

[La tradición se inició] desde el instante en que el gran navegante hincó su rodilla en América, para anunciarle al indígena que el eclipse y el rayo eran castigos divinos lanzados sobre la crueldad, sobre lo sanguinario, sobre la antifé (Congreso de la Nación, 1947, p. 99).

Representaciones de similar carácter al respecto de los indígenas se manifestaron en el contexto del Malón de la Paz. En Buenos Aires, la llegada de la comitiva que había partido desde la Puna encontró entre los congresales un recibimiento a los "hermanos coyas" en apariencia cordial. Al respecto, Adriana Kindgard cita las siguientes palabras:

Vienen trayendo el dolor milenario de la raza, vienen a buscar una reivindicación para el despojo de sus tierras. Ellos no entienden de principios jurídicos, no saben si la propiedad es romanista individualista, no han leído a Ihering ni a Savigny, no han leído nada (...) Son más 
sencillos en su mentalidad de niños (Kindgard, 2004, p.173).

Kindgard (2004) sostiene que en estas declaraciones -proferidas por un parlamentario peronista- se expresó una postura paternalista y se revelaba "la magnitud del etnocentrismo en la sociedad argentina" ( $p$. 173).

El resguardo de la tradición hispánica se expresó también en la provincia de Jujuy durante los años peronistas. Lo más destacable fue que el régimen peronista cambió el nombre de la ciudad capital. En abril de 1950 , en virtud del decreto $N .^{\circ} 8184 / 1950$, el gobernador de la provincia, Alberto Iturbe, dispuso que se restaurase a la metrópoli su antigua denominación; por lo tanto, dejó de llamarse "Jujuy" para ser nombrada "San Salvador de Jujuy" (Municipalidad de San Salvador de Jujuy, 1956).

Los fundamentos del cambio no estuvieron investidos de un carácter plenamente partidario (aunque el texto tuviera una cita a los discursos de Perón), sino más bien histórico. De acuerdo con la normativa, se debía reponer la nominación que le otorgó su fundador; según el acta de institución, Francisco de Argañaraz dispuso: "Que de hoy dicho día en adelante y para siempre jamás se nombre y llame esta dicha Ciudad San Salvador de Velasco en el Valle de Jujuy" (Municipalidad de San Salvador de Jujuy, 1956, p. 1). El retorno a la denominación primigenia -sancionado a pocos días de un nuevo aniversario de su creaciónse basó en el criterio del gobierno peronista en reconocer el carácter histórico del establecimiento de la ciudad.

Que esta fundación tuvo también, como todas las otras, como fin primordial incorporar a los hijos de América a la civilización cristiana;

Que la gesta de España, descubrimiento, conquista y fundación, donde se confundieron los héroes y los santos con la cruz y la espada -como ha dicho el Presidente General Perón- ha sido una empresa cuyo cometido la Antigüedad clásica la hubiera discernido a los dioses, pero aquí fue cumplida por hombres que no eran dioses, aunque los impulsaba el soplo divino de una fe que los hacía creados a imagen y semejanza de Dios; 
Que por ello, armonizando hecho y espíritu, el mejor homenaje para honrar el aniversario de más de tres y media centuria de nuestra "muy leal y constante ciudad" es restaurarle su nombre primitivo de San Salvador (Municipalidad de San Salvador de Jujuy, 1956, p. 1).

En los fundamentos citados, se pone de manifiesto la tríada mencionada anteriormente: la gesta de la fundación de la ciudad radicaba en la junción de la hispanidad, la civilización y el catolicismo. La justificación del retorno al nombre original evidencia también la preconización que el gobierno peronista provincial hacía de la trilogía en cuestión y su asociación con la misma.

Los rasgos hispanófilos se expresaron también en otros actos oficiales. En octubre de 1953, por ejemplo, se celebró en las instalaciones de la Sociedad Española local un aniversario del "Día de la Raza". En tal ocasión, el gobernador aseveró lo siguiente: "Amar a España significa de por sí un signo de cultura"; en su discurso, preconizó además las "artes españolas", fundamentalmente las letras, citando incluso pasajes de la obra de Rubén Darío (“Amar a España”, 1953, 14 de octubre). En este caso, se omite la referencia al catolicismo; no obstante, el vínculo entre civilidad y lo hispánico se mantiene inmune.

\section{Medios gráficos, antiperonismo y racismo}

El objetivo explícito del gobierno "revolucionario" contemplaba la erradicación del peronismo; tal resultado comportaba no solo suprimirlo de la esfera pública, sino extirparlo totalmente. En función de tal objetivo, el gobierno daría lugar a una normativa novedosa; basada en la proscripción y la censura, reformularía radicalmente el desarrollo de las prácticas de la prensa. Las reglas sancionadas hicieron posible que por primera vez en Argentina se prohibiera "la utilización de términos y expresiones, al punto que el decreto-ley 4161, que reglamentó esas cortapisas, impuso el recurso a ciertos eufemismos por medio de los cuales (...) referirse al 'régimen depuesto' o a sus símbolos" (Da Orden y Melon-Pirro, 2007, p. 20). La proscripción del peronismo modificó las políticas públicas con respecto a la prensa; las estrategias de la "Libertadora" alteraron los límites de lo decible y condicionaron la expresión pública de las ideas.

En la provincia de Jujuy, la prensa también adhirió a los postulados que 
en adelante regirían la producción del discurso noticioso. La flexibilidad de los diarios de Jujuy con respecto a los principios políticos oficiales se manifestaría también frente al pronto cambio de autoridades nacionales. Luego de solo dos meses de gobierno, el general Lonardi, el presidente que había asumido inmediatamente después de la deposición de Perón, fue destituido de su cargo. Su gestión, con amplia representación del sector nacionalista, fue acusada por el bando liberal del antiperonismo de favorecer el mantenimiento de los rasgos autoritarios de la tutela justicialista.

La remoción de las autoridades nacionalistas en manos de la línea liberal favoreció la restauración de principios de interpelación de manifiesta simpatía con el liberalismo vernáculo. La reposición de este último como principio fundante y organizador de la política supondría la restitución de la libertad como condición ineludible para las prácticas políticas y asimismo, las periodísticas. El proceso supondría la continuidad -por decirlo de algún modo- de las luchas constitutivas del antiperonismo. La dictadura militar consagrada en junio de 1943 había sido identificada como la reproducción local de los fascismos europeos. Idéntico mote le cabría a su sucesor: el peronismo, reconocido como el heredero del gobierno castrense que había conculcado los principios de Argentina liberal, también habría de enfrentar la acusación de salvaguardar los intereses de sus aliados nacionalistas y católicos integristas.

El triunfo de las fuerzas liberales -consumado mediante la deposición del general Lonardi- encontraría eco rápidamente en la prensa de la provincia de Jujuy. Los medios interpelaron al gobierno de la Revolución Libertadora y demandaron la operacionalización de políticas que ejecutasen el proceso de desperonización. Tales requisitorias se expresaron en múltiples propuestas, entre estas, la modificación del espacio público; tal medida se expresaría en el pedido de cambio de las designaciones de las calles de San Salvador de Jujuy.

El gobierno anterior [peronista] se caracterizó por el prurito de designar con nombres nuevos a las calles, plazas y lugares tradicionalmente conocidos con denominaciones enquistadas en el hábito o en la costumbre popular. Fue así que a diferentes arterias y núcleos poblados se les puso "17 de octubre", avenida "Juan Perón", calle "Eva Perón", ciudad "Evita", "Pasaje 
Justicialista" y otro género de nomenclaturas coincidentes con el fervor partidario ("El nombre dado", 1955, 6 de diciembre).

Considerada una aberración por el antiperonismo, la institución de tales apelativos demandaba, una vez destituidos sus promotores, una necesaria erradicación. A los nombres citados-productos incuestionables de la imaginería justicialista-, debe agregarse además la designación de una plaza como "Tupac Amaru" y la redenominación del Río Chico como "Xibi Xibi". ${ }^{2}$ Tales designaciones -cabe señalar- rompían con el esquema peronista de otorgarse tributo estrictamente a sí mismo; además, mientras introducía de manera novedosa el reconocimiento de lo originario, irrumpía también en contra de los principios de la civilidad hispánica defendidos en las querellas por la revalidación de la enseñanza religiosa.

La campaña de desperonización pregonada por la prensa no solo formuló argumentos condenatorios contra las preconizaciones del gobierno depuesto, sino que además, en el caso específico del diario Crónica, constituyó fundamentos particulares con el fin de eliminar los nombres de raigambre indígena.

Aun dadas las coincidencias con el conjunto de la prensa antiperonista en cuanto a la execración del peronismo, cabe señalar que la especificidad de Crónica se asentó en que fue el único medio en la provincia de Jujuy en el que preponderaron los rasgos racistas del antiperonismo. La posición asumida por Crónica al respecto del tratamiento brindado a los sectores originarios abrevó en la tesitura antiperonista que preconizaba el carácter civilizado autoconferido en detrimento de la naturaleza bárbara asignada al peronismo. La prédica "desperonizadora" de este diario transitó así el camino abierto en los albores del peronismo por sus detractores, al tiempo que representaba estos rasgos del imaginario antiperonista en el contexto del espacio público provincial. En este sentido, la agenda de esta empresa periodística no constituyó un hecho estrictamente singular, en la medida que apelaba a una tradición discursiva arraigada y operaba como portavoz de un sector que estructuró el campo sociopolítico en función de la dicotomía civilización y barbarie.

2 El Río Chico y el Río Grande son los dos cursos hídricos que rodean el casco histórico de la ciudad de San Salvador de Jujuy. 
Una de las particularidades de la cruzada iniciada por Crónica estuvo dada en el salvaguardo de España. Paradójica forma, en apariencia, de ovacionar la victoria del bando liberal sobre los "resabios del totalitarismo", en ningún momento cuestionó la hispanidad; por el contrario, consideró a España y la colonia como la fuente de la civilización en América. En una editorial, enunciaba lo siguiente:
Estamos lejos de negarle a nuestra Madre Patria, de la cual somos los legítimos herederos raciales, sus prestancias, sus privilegios y su grandeza en la empresa colosal de haber incorporado al mundo un continente donde la cultura hispánica, con la lengua castellana, viene dando tantas pruebas de civilidad con el concierto de los demás pueblos del orbe ("Hay un dislate", 1955, 18 de noviembre).

El artículo en cuestión contiene dos elementos en torno a los cuales se estructura: civilidad y raza. Las tendencias coincidentes entre esta proclama y los argumentos a favor del catolicismo de mediados de los 40 son evidentes, mas se contraponen precisamente en la remoción del vínculo filiatorio entre lo hispánico y la religión católica. No obstante, esta disyunción con evidente influencia liberal, sí se pone de manifiesto el lugar de la raza en el planteo del medio gráfico. La nota -titulada "Hay un dislate en ciertos nombres asignados a calles y lugares públicos en Jujuy" $\neg-$ concluía: "Tupac Amarú es otra de las anomalías que deben desaparecer" ("Hay un dislate", 1955, 18 de noviembre).

En una siguiente editorial, Crónica manifestó nuevamente su preocupación por la continuidad de nomenclaturas de naturaleza cuestionable, que adjudicó afanosamente el gobierno peronista. "El Río Chico adopta una denominación aborigen [Xibi-Xibi]". El puente Lavalle, tendido sobre el curso de agua mencionado, fue designado también Xibi-Xibi. El diario planteó con desasosiego -y con cierto alivio ciertamente- que poco había faltado que el Río Grande fuese investido con su nomenclatura de antaño: "Río de las Humahuacas" ("El gobierno depuesto", 1955, 19 de noviembre). No obstante la explícita conmoción con la que el periódico se refería al origen de tales nombres, su concepción sobre raza y salvajismo emergió fuertemente en una serie de apostillas orientadas a exhortar mediante fundamentos históricos la consumación del proceso de supresión. 
[En 1785] Tupac Amarúc, un profeta de la raza incaica, que se titulaba descendiente directo del imperio que tenía su sede en el Cuzco, lanzó su grito de rebelión, convulsionando a todo el Perú, incluso La Paz, Oruro y Cochabamba, alcanzando la insurrección a los indios tobas, aliados de los matacos en toda la región jujeña, con repercusión en el Chaco.

En este confín [Jujuy] asumió la defensa el gobernador Gregorio Zegada. Aplasta el levantamiento, salvando esta ciudad de caer bajo la saña de los indígenas que se preparaban a arrasar la población con una razia cruel y sin precedentes (“La Muy Leal”, 1955, 28 de noviembre).

Posteriormente, Crónica publicó una editorial coincidente con la anterior, en la que el mismo concepto discurría con diversas palabras:

La insurrección aborigen provocada por aquel espurio descendiente de los Incas, puso a Jujuy en riesgo de ser arrasada en 1781. Los secuaces de Tupac-Amarú, con las tribus tobas y las legiones de matacos que se habían desencadenado desde el Chaco, situándose en las zonas de Zapla y del Pongo, se encontraron a las puertas de esta ciudad, cuyos vecinos estuvieron en inminencia de ser exterminados por las hordas ("El nombre dado", 1955, 6 de diciembre).

Las afirmaciones precedentes se organizaron en dos momentos: primero, la puesta en evidencia de un proceso de diferenciación entre la civilización -representada por la ciudad-y el salvajismo, encarnado en la alianza de colectivos "carentes de ilustración". Segundo, se manifiestan dos predisposiciones divergentes con respecto a la civilidad; por un lado, la gobernación, delegada de los intereses coloniales, constituyó la salvaguardia de la urbe jujeña; por el otro, la tendencia al saqueo, la devastación y el aniquilamiento que se cernieron sobre la ciudad.

Crónica manifestaba exacerbada crispación al referirse a la omisión cometida por el régimen peronista de nombrar a una plaza de San Salvador de Jujuy con el nombre de tal heredero de los incas. Suponía el diario que el peronismo no había reprimido la reminiscencia de hechos considerados indiscutiblemente de carácter traumático. En una editorial, 
el periódico concluyó: "La rebelión de Tupac Amarú estuvo a punto de hacer desaparecer a Jujuy, con todo su plantel humano. Por esta razón no merece ser perpetuada en el recuerdo" ("El nombre dado", 1955, 6 de diciembre).

La posición racista del diario buscaba desterrar o cancelar de la memoria las remembranzas vinculadas con la rebelión. Visto desde otra perspectiva, Crónica apuntaba a instalar una memoria específica con respecto a las rebeliones indígenas y, asimismo, a cuestionar el presunto reconocimiento del que habrían sido investidos por el peronismo. El medio gráfico esperó que el proceso de encuadre de la memoria, a la que se refiere Pollak (1989), cancelase del relato estatal y legítimo las "correrías" de Túpac Amaru. ${ }^{3}$

La extrañeza de Crónica frente a los nombramientos de los lugares públicos, con designaciones como Xibi-Xibi, y la enérgica impetración para su supresión, conllevaba la expresión de una forma de antiperonismo que desbordaba lo estrictamente político. Las denominaciones de las calles supuso la enajenación a la ciudad de parte de sus principios de civilidad, que comportaban la limitación o el exterminio de la no ilustración en su seno. El despojo en manos del peronismo generó en Crónica la atribución de forjar un vínculo asociativo entre el gobierno derrocado y los indígenas.

Tal conjunción fue reforzada en función del encarcelamiento de un oficial de la policía,sospechoso de torturar durante los años peronistas; los suplicios que este presuntamente habría aplicado sobre un detenido constituían una afrenta a los derechos civiles. No obstante, el diario también hizo mención al nombre del agente policial:

[El gobierno provincial] ha ordenado la detención del oficial inspector de la policía, llamado Macrobio Vilca (...) por hechos de agresión (...)

Hay en la vida ciertos especímenes con nombres y apellidos que tienen estrecha vinculación o semejanza con su idiosincrasia, su índole, sus inclinaciones y sus modalidades (...)

3 El encuadramiento de la memoria, sugiere Pollak (1989), supone proveer un esquema de referencias y de puntos de referencias, de manera tal de limitar las posibilidades interpretativas del pasado 
El apellido Vilca, por otra parte, tiene una raigambre netamente aborigen, lo que da que pensar que este mismo sujeto obedece en su temperamento a ancestrales designios. Es indudable que el indio le salta a cada paso, no pudiendo dominar, por falta de autocontrol sus nervicios y su paranoica brutalidad de hombre de tendencia cavernaria ("Merece un prolongado", 1956, 21 de junio).

El ligamen entre peronismo y el salvajismo no se infirió siguiendo las presuntas preferencias históricas del primero, sino a partir de la filiación del acusado y, también, su ascendencia. Dicho de otra forma, el policía en cuestión era considerado como la junción entre peronista y salvaje.

\section{Reflexiones finales}

La deposición del peronismo supuso un proceso pletórico en mutaciones con respecto al orden caído; en lo que concierne a la prensa, su regulación bajo nuevas disposiciones conllevó la cancelación de los discursos peronistas en beneficio de la emergencia de nuevas orientaciones. No obstante, aunque los medios seguían la línea editorial favorecida por el gobierno militar, se convirtieron en agentes que interpelaban y demandaban al Estado la instauración y supresión de políticas. La remoción de los nombres de lugares públicos asociados al peronismo constituyó una de esas demandas.

La proscripción del peronismo benefició el advenimiento de representaciones silenciadas durante la década precedente. El reflorecimiento de tendencias racistas contribuyó a dar curso a prescripciones que, aunque no eran peculiaridad estricta del antiperonismo, favoreció al menos la redefinición de cierto sector.

El racismo manifestado en las editoriales de Crónica expresó también que un principio de diferenciación en apariencia pueril como la biología contiene una dimensión política. La civilidad que defendía tal medio suponía la conquista y la supresión de los indígenas, estaba inscrita en las tensiones entre los postulados sarmientinos de Facundo, la omisión del catolicismo, la exacerbación del liberalismo y la exaltación del pasado hispánico, además de la extirpación del recuerdo de la raza de los incas, 
todo esto constituyó una forma específica de darle forma y contenido al antiperonismo.

\section{Referencias}

Amar a España significa de por sí un signo de cultura. (14 de octubre de 1953). Jujuy, p. 1.

Bianchi, S. (1992). Iglesia católica y peronismo: la cuestión de la enseñanza religiosa (1946-1955). Estudios Interdisciplinarios de América Latina y el Caribe, 3 (2). Recuperado de http://www. tau.ac.il/eial/III_2/bianchi.htm

Ciria, A. (1983). Política y cultura popular: la Argentina peronista 19461955. Buenos Aires: Ediciones de la Flor. Ir a libro: http://books. google.co.cr/books/about/Pol\%C3\%ADtica_y_Cultura_Popular. html?id=x84ZAAAAYAAJ\&redir_esc=y

Congreso de la Nación. (1947). La Enseñanza Religiosa. Discursos pronunciados en la Honorable Cámara de Diputados de la Nación. Buenos Aires: Congreso de la Nación. Ir a documento: http://books.google.com.ar/books/about/El_debate_sobre_la_ ense\%C3\%B1anza_religiosa.html?id=mssbAAAAIAAJ\&redir_ esc $=y$

Da Orden, L. y Melon-Pirro, J. C. (Comps.). (2007). Prensa y peronismo. El problema y el tratamiento de las fuentes. En L. Da Orden y J. C Melon-Pirro (Eds.), Prensa y peronismo. Discursos, prácticas, empresas (1943-1958) (pp. 9-25). Rosario: Prohistoria http:// www.prohistoria.com.ar/ediciones/catalog/product_info. php?products_id $=51$

El gobierno depuesto se caracterizó por una serie de heteróclitas denominaciones. (19 de noviembre de 1955). Crónica, p. 1.

El nombre dado a una plazoleta importa un flagrante dislate. (6 de diciembre de 1955). Crónica, p. 1. 
García-Sebastiani, M. (2005). Los antiperonistas en la Argentina peronista: radicales y socialistas en la política Argentina entre 1943 y 1951. Buenos Aires: Prometeo Libros. Ir a libro: http://www. prometeolibros.com.ar/MainSite/Libro/antiperonistas-en-laargentina-peronistas-los-radicales-y-socialistas-en-la-politica/ marcela-garcia-sebastiani/ldLibro331363

Hay un dislate en ciertos nombres asignados a calles y lugares públicos en Jujuy. (18 de noviembre de 1955). Crónica, p. 1.

Herrera, C. M. (2005). ¿La hipótesis de Ghioldi? El socialismo y la caracterización del peronismo (1943-1956). En H. Camarero; C. Herrera y A. Bisso (Eds.), El Partido Socialista en Argentina: sociedad, política e ideas a través de un siglo (pp. 343-366). Buenos Aires: Prometeo Libros. Ir a libro: http://www. prometeoeditorial.com/catalogo/detalle.php?id_libro $=29$

Kindgard, A. (2001). Alianzas y enfrentamientos en los orígenes del peronismo jujeño. Argentina: Universidad Nacional de Jujuy, Unidad de Investigación en Historia Regional. Ir a libro: http://books.google.co.cr/books/ about/Alianzas_y_enfrentamientos_en_los_or\%C3\%ADge. html?id=QZduAAAAMAAJ\&redir_esc=y

Kindgard, A. (2004). Tradición y conflicto social en los Andes argentinos. En torno al Malón de la Paz de 1946. Estudios Interdisciplinarios de América Latina y el Caribe, 15(1). Recuperado de http://www1.tau.ac.il/eial/index.php?option=com content\&task=view\&id=371\&ltemid=193

La Muy Leal y Constante ciudad de San Salvador de Jujuy. (28 de noviembre de 1955). Crónica, p. 1.

Merece un prolongado y quizá un inextinguible aplauso una medida de la Intervención. (21 de junio de 1956). Crónica, p. 1.

Municipalidad de San Salvador de Jujuy, Argentina. (1956). Expediente $\mathrm{N}^{\circ} 316 / \mathrm{M} / 1956$. 
Pollak, M. (1989). Memória, esquecimento, silencio. Estudos Históricos, 2(3), 3-15. Recuperado de http://www.uel.br/cch/cdph/arqtxt/ Memoria_esquecimento_silencio.pdf

Svampa, M. (2010). El dilema argentino: civilización o barbarie. Buenos Aires: Taurus. Ir a libro: http://www.maristellasvampa.net/librodilema.shtml

Teruel, A. (2006). Panorama económico y socio-demográfico en la larga duración (siglos $X I X$ y XX). En A. Teruel y M. Lagos (Dir.), Jujuy en la historia. De la colonia al siglo XX (pp. 295-345). San Salvador de Jujuy: Ediunju. Ir a libro: http://www.reun.com.ar/ libro. .php?\&id=379

Torre, J. C. (2002). Introducción a los años peronistas. En J. C. Torre

(Ed.), Los años peronistas (1943-1955) (pp. 12-77). Buenos Aires: Editorial Sudamericana. Ir a libro: http://www.fcp.uncu.edu.ar/ upload/Torre,_Juan_Carlos_Introduccin_a_los_aos_peronistas. pdf

Torre, J. C. (1995). El 17 de Octubre de 1945. Buenos Aires: Ariel. 